\title{
Multi-ligament injures of the knee: does the age matter? A long-term retrospective study
}

\author{
N. Zimmermann, L.B. Moser, M.T. Hirschmann \\ Department of Orthopaedic Surgery and Traumatology, Kantonsspital Baselland, Bruderholz, Switzerland
}

\author{
CORRESPONDING AUTHOR \\ Michael T. Hirschmann \\ Kantonsspital Baselland (Bruderholz, \\ Liestal, Laufen) \\ Department of Orthopaedic Surgery \\ and Traumatology \\ $\mathrm{CH}-4101$ Bruderholz, Switzerland \\ Phone: +41765105865 \\ Fax: +41614363676 \\ E-mail: Michael.Hirschmann@unibas.ch \\ DOI \\ 10.32098/mltj.01.2019.06
}

\begin{abstract}
SUMMARY
Background. The aim of this large retrospective long-term study was to investigate if age can be considered as prognostic factor for inferior outcomes after treatment of multi-ligament injuries of the knee. Methods. A retrospective study of the long-term outcomes of patients $(\mathrm{n}=89)$ treated with multi-ligament injured knees was performed. Four age groups $(<$ or $>$ 28 years at injury and $<$ or $>41$ years at follow-up) were investigated. The visual analogue scale (pain and satisfaction), Lysholm score, Tegner score, Knee Society Score, SF-36 health questionnaire, cruciate ligament laxity by KT-1000, IKDC2000, need for workers' compensation, conventional and stress radiographs were assessed. Pearson correlations and t-tests were used to test for differences between the groups $(\mathrm{p}<0.05)$. Results. Sixty-eight patients with a follow-up of $12 \pm 8$ years showed no significant difference with regards to age groups at follow-up in the total SF-36 health questionnaire, the VAS pain, VAS satisfaction, the total Knee Society score, the Tegner score (before, after and relative), the need for workers' compensation and the change of occupation. Conclusion. This study showed no significant correlation between the age of patients at injury and the outcomes after multi-ligament knee injuries. It seems that other factors such as injury pattern are more important factors for outcomes after multi-ligament knee injuries than age.
\end{abstract}

\section{KEYWORDS}

multi-ligament injury; age; anterior cruciate ligament; posterior cruciate ligament; traumatic knee dislocation

\section{BACKGROUND}

Traumatic knee dislocation is a rare but devastating knee injury. It is more often caused by high velocity than low velocity accidents (1). Often it is referred to as multi-ligament injury, as it typically results in a rupture of both cruciate ligaments and at least one additional peripheral knee structure such as the medial or lateral collateral ligament. Furthermore, a multi-ligamentous injury is often accompanied by injuries of the menisci, capsule and less frequently by fractures and neurovascular lesions (2).

Treatment of such multi-ligament injuries is either a direct primary repair or reconstruction of all or parts of the injured ligaments. In sedentary patients with low functional demands immobilisation in a brace might be an option.

The time interval from injury has been considered an important factor for outcome in this challenging group of patients, which is documented in a considerable number of studies.
However, the patients' age as negative prognostic factor is still under debate. Age is an important factor in several modern therapeutic decision-making systems in orthopaedic surgery. Generally, one can state that with increasing age the healing capacity of soft tissue decreases and this then might lead to inferior outcomes.

Traditionally a higher age at time of injury is considered as worse prognostic factor, albeit data is lacking for patients with multi-ligament injured knees. Most studies on multi-ligament injured knees did not investigate the influence of age on clinical outcomes (3-12).

Hence, it was the purpose of this study to perform a single-centre retrospective study and compare the long-term outcomes of younger and older patients. It was hypothesized that patients' age has a significant influence on subjective and objective clinical and functional outcomes after multi-ligament injuries to the knee. 


\section{MATERIALS AND METHODS}

All patients who had undergone surgery for multi-ligament injury of the knee between January 1980 and August 2006 were retrospectively investigated, yielding 89 patients (table I). Only patients who had been primarily treated at a single centre with complete open reconstruction of all injured knee structures were included. Figure 1 shows a patient flow chart and the selection process, leading to a total of 68 patients. In 5 cases participation was denied and only 2 were lost to follow-up.

The treatment strategy was a one stage regimen aiming for an open complete ligament reconstruction on both the central pivot and the peripheral injuries. The anterior cruciate ligament (ACL) as well as the posterior cruciate ligament (PCL) were treated with primary reconstruction or direct refixation in the case of bony avulsions. The collaterals and posteromedial and posteromedial corner structures were directly repaired in order to get the best possible anatomical restoration of the biomechanics of the knee joint. The detailed treatment algorithm has been previously described (13).

The follow-up time was $12 \pm 8$ years (range 1-34). Of the 68 patients, 58 were males and 10 females. All patients had an injury of both the ACL and the PCL, according to the inclusion criteria.

Among the younger subjects a sports accident $(54.3 \%$ ) was the most common cause. A work-related injury was more frequent in older $(15.2 \%)$ than in younger $(5.7 \%)$ patients. Almost all additional injuries were less common in older patients. Similar in terms of frequency were lesions of the superficial MCL ( $71.4 \%$ vs. $72.7 \%$ ), the deep MCL $(65.7 \%$ vs. $63.6 \%)$ as well as of the medial meniscus $(22.9 \%$ vs. $21.2 \%)$. More than twice as frequent in younger patients

Table I: Demographics

\begin{tabular}{ll}
\hline Mean age at injury (years) & $30 \pm 11$ \\
\hline Side of injury (right,left) & $\mathrm{n}=32(47 \%), \mathrm{n}=36(53 \%)$ \\
\hline Gender (male, female) & $\mathrm{n}=58(85 \%), \mathrm{n}=10(15 \%)$ \\
\hline Mean height $(\mathbf{c m})$ & $176 \pm 8$ \\
\hline Mean weight $(\mathbf{k g})$ & $79 \pm 11$ \\
\hline BMI & $25 \pm 3$ \\
\hline Insurance status (private, public) & $\mathrm{n}=19(28 \%), \mathrm{n}=49(72 \%)$ \\
\hline Sport activity prior trauma & \\
\hline none & $\mathrm{n}=11(17 \%)$ \\
\hline only rarely & $\mathrm{n}=33(50 \%)$ \\
\hline regularly & $\mathrm{n}=22(32 \%)$ \\
\hline not comment & $\mathrm{n}=2(3 \%)$ \\
\hline
\end{tabular}

Muscles, Ligaments and Tendons Journal 2019;9 (1)



Figure 1 - Patient selection.

were injuries of the LCL ( $45.7 \%$ vs. $18.2 \%)$, of the lateral meniscus $(40.0 \%$ vs. $18.2 \%)$ and of the biceps tendon $(17.1 \%$ vs. $6.1 \%)$. Only fractures $(12.1 \%$ vs. $2.9 \%)$ and semimembranosus muscle lesions $(9.1 \%$ vs. $5.7 \%)$ were more common in older patients. The most common injury overall was a lesion of the superficial MCL, followed by the deep MCL (table II).

Table II - Patients demographics.

\begin{tabular}{ll}
\hline smoking & $\mathrm{n}=33(49 \%)$ \\
\hline injury pattern & \\
\hline ACL & $\mathrm{n}=68(100 \%)$ \\
\hline PCL & $\mathrm{n}=68(100 \%)$ \\
\hline PCL & $\mathrm{n}=49(72 \%)$ \\
\hline medial meniscus & $\mathrm{n}=44(65 \%)$ \\
\hline semimembranosus muscle & $\mathrm{n}=15(22 \%)$ \\
\hline LCL & $\mathrm{n}=5(7 \%)$ \\
\hline popliteus tendon & $\mathrm{n}=22(32 \%)$ \\
\hline biceps tendon & $\mathrm{n}=21(31 \%)$ \\
\hline lateral meniscus & $\mathrm{n}=8(12 \%)$ \\
\hline peroneal nerve & $\mathrm{n}=20(29 \%)$ \\
\hline popliteal artery (intimal) & $\mathrm{n}=3(4 \%)$ \\
\hline
\end{tabular}


The most common injuries in younger patients were sports-related $(54.5 \%)$, whereas in older ones these were motor vehicle accidents $(45.7 \%)$.

The most common lesion was a lesion of the superficial MCL, which occurred in $69.7 \%$ of the older and $74.3 \%$ of the younger patients, followed by the deep MCL $(60.6 \%$ and $68.6 \%$ ). The differences between younger and older patients were inhomogeneous, as described in table III. ACL lesions were treated by ACL reconstruction in 48 patients (71\%), by refixation in 10 patients $(15 \%)$ and by suture in 10 patients $(15 \%)$. The PCL was refixated in 27 patients $(40 \%)$, sutured in 19 patients $(28 \%)$ and reconstructed in $21(31 \%)$ patients. Overall, 13 patients (19\%) had a repair of both the ACL and the PCL and 14 patients $(21 \%)$ had a reconstruction of both cruciate ligaments. The most common additional procedure was primary repair of the MCL (60\%). The LCL was primarily repaired in $31 \%$ of the cases. Sutures of the lateral $(31 \%)$ and of the medial $(22 \%)$ meniscus were more frequent than partial meniscectomy (10\%). A reconstruction of the peroneal nerve was needed in $3 \%$ of patients. A vascular reconstruction was not necessary.

The patients were then divided into subgroups according to their age, using the median as threshold. At the time of the accident the whole study population was divided into two groups with 35 subjects under and 33 patients over 28 years of age (median 27.9 years). At last follow-up there were 33 patients younger than 41 and 35 patients older than age 41 years (median 41.3 years).
The follow-up was done by an independent orthopedic surgeon not being involved in the previous treatment. The clinical outcome was assessed using the IKDC2000 (International Knee Documentation Committee Standard Evaluation Form), the SF36 (short form 36), a visual analogue scale (VAS) for pain (0-10) and satisfaction (10-0), the Lysholm score $(14,15)$, the Tegner score and the Knee society score (KSS) .

The stability of the ligaments was assessed through Lachman test, drawer test, pivot shift and varus/valgus stress in $30^{\circ}$ flexion. Ligament laxity was quantified using a KT-1000 arthrometer (Medmetric, San Diego, U.S.A.) with forces of $67 \mathrm{~N}, 89 \mathrm{~N}$ and $134 \mathrm{~N}$ in $25^{\circ}$ flexion.

The study was approved by the local ethics committee (EK 307/06). All procedures performed, were in accordance with the ethical standards of the institutional and/or national research committee and with the 1964 Declaration of Helsinki and its later amendments or comparable ethical standards. Informed consent was obtained from all individual participants included in the study.

\section{Statistical analysis}

Discrete variables were recorded as absolute and relative frequencies. The means, standard deviations and ranges of continuous variables were calculated. If a value was missing, the mean was used instead. Correlations between groups were made using the Pearson's correlation. A statis-

Table III - Injury $(n=68)$.

\begin{tabular}{|c|c|c|c|c|}
\hline & age at injury $<28$ & age at injury $>28$ & age at follow-up $<41$ & age at follow-up $>41$ \\
\hline \multicolumn{5}{|l|}{ Types of injuries } \\
\hline sports-related injury & $19(54.3 \%)$ & $14(42.4 \%)$ & $18(54.5 \%)$ & $15(42.9 \%)$ \\
\hline work-related injury & $35(5.7 \%)$ & $40(15.2 \%)$ & $38(9.1 \%)$ & $37(11.4 \%)$ \\
\hline \multicolumn{5}{|l|}{ Injury pattern } \\
\hline LCL & $16(45.7 \%)$ & $6(18.2 \%)$ & $12(36.4 \%)$ & $10(28.6 \%)$ \\
\hline medial meniscus & $8(22.9 \%)$ & $7(21.2 \%)$ & $9(27.3 \%)$ & $6(17.1 \%)$ \\
\hline lateral meniscus & $14(40.0 \%)$ & $6(18.2 \%)$ & $8(24.2 \%)$ & $12(34.3 \%)$ \\
\hline popliteus tendon & $13(37.1 \%)$ & $8(24.2 \%)$ & $11(33.3 \%)$ & $10(28.6 \%)$ \\
\hline semimembranosus muscle & $2(5.7 \%)$ & $3(9.1 \%)$ & $2(6.1 \%)$ & $3(8.6 \%)$ \\
\hline peroneal nerve & $2(5.7 \%)$ & $1(3.0 \%)$ & $2(6.1 \%)$ & $1(2.9 \%)$ \\
\hline
\end{tabular}


tical difference between the groups of older and younger patients was sought. The t-test was performed and a p-value of $<0.05$ was considered as statistically significant. A post hoc sample size analysis showed significant sample size for the study questions analysed.

The calculations were performed using statistical package for the social sciences (SPSS) for Windows, version 13.0 (Chicago, U.S.A.).

\section{RESULTS}

When considering age at injury the Knee Society score was higher in older (188.03 +/- 16.59) than in younger (185.38 + /- 13.8) patients. There low pain scores in both groups (VAS $1.51+/-1.65$ and $1.18+/-1.61$ ). After injury there was a decreased Tegner score by $0.67+/-0.28$ in younger and by $0.72+/-0.29$ in older patients. Likewise, the relative Lysholm score was $0.83+/-0.17$ in younger and $0.88+/$ 0.16 in older subjects. Furthermore, younger patients had slightly more need for secondary surgeries $(0.51+/-0.51$ vs. $0.42+/-0.5)$ and for workers compensation $(0.11+/-0.32$ vs. $0.09+/-0.29$ ).

When considering age at follow-up the Knee Society score was the same among all patients and not dependent from age. There was a high level of satisfaction in both younger (VAS $8.58+/$ - 1.58) and older (VAS 8.91+/- 1.25) patients. The Tegner score postoperatively decreased more in younger $(0.75+/-0.27)$ than in older $(0.64+/-0.3)$ patients. The relative Lysholm score was not statistically different in the younger $(0.85+/-0.16)$ and in the older $(0.86+/-0.18)$ patients' group.
A lower Tegner score, representing lower sports activity level, was found with higher age at injury and at follow-up $(p<0.05)$. In all patients the need for secondary surgeries were more frequent with higher age $(\mathrm{p}<0.05)$.

When considering age at follow-up it was seen that in the patients' group under 41 years, a higher age led to a decreased Lysholm score on the injured side $(\mathrm{p}<0.05)$. In the patients' group over 41 years a higher age at injury led to a greater increase of the Lysholm score $(\mathrm{p}<0.05)$. In both groups, the longer the time was which had passed since the injury the more secondary surgeries were performed $(\mathrm{p}<$ 0.05 , table III-V).

\section{DISCUSSION}

The most important finding of the present study was that clinical and functional long-term outcomes after surgical treatment of multi-ligament injured knees are not significantly influenced by age of the patient at time of injury. Based on the findings of the present study, age at time of surgery has no significant correlation with SF-36 health questionnaire, VAS pain, VAS satisfaction, the Knee Society Score or even the need for worker's compensation. Furthermore, the age at last follow-up did also not significantly influence sports activity reflected by the Tegner score or the need to change the occupation. The only positive correlation was found for age at time of injury and the Tegner score as well as the need for secondary surgery. In addition, the Lysholm score showed few positive correlations with age. However, as there were only few correlations positive a possible correlation bias cannot be excluded. It might be that these were only positive

Table IV - Subjective and objective outcomes at last follow-up.

\begin{tabular}{lcccc}
\hline & age at injury < 28 & age at injury $>\mathbf{2 8}$ & age at follow-up < 41 & age at follow-up > 41 \\
\hline Knee Society score & $185.38(+/-13.8)$ & $188.03(+/-16.59)$ & $186.94(+/-14.08)$ & $186.46(+/-16.32)$ \\
\hline VAS pain & $1.51(+/-1.65)$ & $1.18(+/-1.61)$ & $1.55(+/-1.73)$ & $1.17(+/-1.52)$ \\
\hline VAS satisfaction & $8.57(+/-1.5)$ & $8.94(+/-1.32)$ & $8.58(+/-1.58)$ & $8.91(+/-1.25)$ \\
\hline Tegner score preinjury & $7.6(+/-1.75)$ & $6.36(+/-1.66)$ & $7.88(+/-1.76)$ & $6.17(+/-1.42)$ \\
\hline Tegner score at follow-up & $5.03(+/-2.41)$ & $4.67(+/-2.38)$ & $5.85(+/-2.5)$ & $3.91(+/-1.85)$ \\
\hline relative Tegner score & $0.67(+/-0.28)$ & $0.72(+/-0.29)$ & $0.75(+/-0.27)$ & $0.64(+/-0.3)$ \\
\hline Lysholm score uninjured side & $96.89(+/-9.15)$ & $98.48(+/-3.83)$ & $98.06(+/-7.89)$ & $97.29(+/-6.31)$ \\
\hline Lysholm score injured side & $79.97(+/-17.19)$ & $86.45(+/-16.02)$ & $82.76(+/-16.4)$ & $83.46(+/-17.46)$ \\
\hline relative Lysholm score & $0.83(+/-0.17)$ & $0.88(+/-0.16)$ & $0.85(+/-0.16)$ & $0.86(+/-0.18)$ \\
\hline secondary surgeries & $0.51(+/-0.51)$ & $0.42(+/-0.5)$ & $0.33(+/-0.48)$ & $0.6(+/-0.5)$ \\
\hline workers compensation & $0.11(+/-0.32)$ & $0.09(+/-0.29)$ & $0.12(+/-0.33)$ & $0.09(+/-0.28)$ \\
\hline change $)$ & $0.18(+/-0.39)$ & $0.15(+/-0.36)$ & $0.2(+/-0.41)$ \\
\hline
\end{tabular}


Table V - Univariate analysis of outcome data.

\begin{tabular}{|c|c|c|c|c|c|c|}
\hline & \multicolumn{6}{|c|}{ Age at injury } \\
\hline & \multicolumn{3}{|c|}{ age at injury $<28$} & \multicolumn{3}{|c|}{ age at injury $>28$} \\
\hline & $\begin{array}{c}\text { age at follow- } \\
\text { up }\end{array}$ & age at injury & $\begin{array}{c}\text { years since } \\
\text { injury }\end{array}$ & $\begin{array}{c}\text { age at follow- } \\
\text { up }\end{array}$ & age at injury & $\begin{array}{c}\text { years since } \\
\text { injury }\end{array}$ \\
\hline SF-36 total & -0.025 & -0.119 & 0.028 & -0.016 & 0.106 & -0.150 \\
\hline VAS pain & -0.057 & 0.21 & -0.076 & 0.002 & -0.59 & 0.073 \\
\hline KSS total & -0.045 & -0.227 & 0.057 & -0.189 & -0.097 & -0.173 \\
\hline Tegner before & -0.198 & -0.116 & -0.172 & $-0.464^{2}$ & -0.330 & -0.317 \\
\hline Tegner after & $-0.462^{2}$ & $-0.358^{1}$ & $-0.361^{1}$ & $-0.378^{1}$ & -0.080 & $-0.481^{2}$ \\
\hline Tegner relative & $-0.376^{1}$ & -0.260 & -0.308 & -0.135 & 0.136 & $-0.367^{1}$ \\
\hline Lysholm realtive & -0.266 & -0.207 & -0.207 & 0.251 & 0.199 & 0.147 \\
\hline secondary surgeries & $0.488^{1}$ & 0.136 & $0.496^{2}$ & $0.430^{1}$ & 0.009 & $0.646^{2}$ \\
\hline workers' compensation & -0.102 & 0.238 & -0.232 & -0.103 & -0.109 & -0.028 \\
\hline change of occupation & 0.097 & $0.362^{1}$ & -0.062 & 0.114 & -0.41 & 0.223 \\
\hline
\end{tabular}

\begin{tabular}{|c|c|c|c|c|c|c|}
\hline & \multicolumn{6}{|c|}{ Age at follow-up } \\
\hline & age at follow-up & $\begin{array}{l}\text { age at } \\
\text { injury }\end{array}$ & $\begin{array}{c}\text { years since } \\
\text { injury }\end{array}$ & age at follow-up & age at injury & $\begin{array}{l}\text { years since } \\
\text { injury }\end{array}$ \\
\hline SF-36 total & -0.097 & -0.156 & 0.039 & -0.101 & 0.064 & -0.253 \\
\hline VAS pain & 0.027 & 0.24 & 0.008 & 0.004 & -0.076 & 0.130 \\
\hline KSS total & -0.061 & 0.079 & -0.140 & -0.057 & -0.038 & -0.021 \\
\hline Tegner before & -0.031 & -0.065 & 0.024 & -0.290 & -0.279 & 0.034 \\
\hline Tegner after & -0.216 & -0.041 & -0.200 & 0.033 & 0.232 & -0.332 \\
\hline Tegner relative & -0.231 & 0.008 & -0.261 & 0.154 & 0.320 & -0.301 \\
\hline Lysholm realtive & -0.280 & -0.218 & -0.111 & $0.352^{1}$ & 0.325 & -0.018 \\
\hline secondary surgeries & 0.213 & -0.190 & $0.404^{1}$ & 0.086 & -0.294 & $0.610^{2}$ \\
\hline workers' compensation & 0.011 & 0.062 & -0.043 & -0.169 & -0.027 & -0.203 \\
\hline change of occupation & 0.084 & 0.121 & -0.016 & 0.056 & -0.020 & 0.116 \\
\hline
\end{tabular}

${ }^{1}$ Correlation is significant at the 0.05 level (2-tailed).

${ }^{2}$ Correlation is significant at the 0.01 level (2-tailed). 
by chance. Therefore, the study hypothesis of a correlation between age and the outcome cannot be confirmed.

Only few other studies have focused on the age of patients with multi-ligament injured knees. In contrast to the present study Levy et al. described a lower absolute Lysholm score $(76.9$ vs. $68.5 ; \mathrm{p}=0.04)$ and a lower IKDC (73.3 vs. 61.9; $\mathrm{p}=0.01)$ in patients older than 30 years at surgery (16). A total of 125 patients were included with a followup time of 5 years, which is markedly shorter than in the present study. The average age at surgery was 31 years. In this study the age at injury was not published and might differ from ours due to secondary surgeries (16.8\%). Five different age groups in each 10 -years step were analysed. The youngest being 11 - to 20 years, the oldest $\geq 51$ years. Only a significant difference between the 21 to 30 years age group and the 31 to 40 years age group was found (17.9 points for IKDC and 15.4 points for Lysholm, $\mathrm{p}<0.01$ ). Surprisingly, the middle age group ( 31 to 40 years) had the lowest Lysholm and IKDC scores. Taking all this into consideration one might speculate if not a similar outcome in younger and older patients might have been shown using a different group sizing or statistical analysis. The question is if this is a real finding or just due to chance.

Another study by Richter et al. found that the Tegner and Lysholm scores were significantly higher in patients younger than 40 years of age at time of injury $(17)^{17}$. However, IKDC scores and Lachman test were not reported. The age at injury was 33.5 (15-76) years, which is higher than in the present study. The authors described 89 patients and studied the follow-up on 77 of them after surgical or conservative treatment with a shorter mean follow-up time (8.2 years). The reported inferior outcome in older patients might also be influenced by more conservative regimens in the older patient group. Unfortunately, it is not clear how old the patients were who received which treatment, nor how many of them did have a follow-up.

\section{REFERENCES}

1. Wascher DC, Dvirnak PC, DeCoster TA. Knee dislocation: initial assessment and implications for treatment. J Orthop Trauma 1997; 11(7):525-529.

2. Hirschmann MT, Muller W. Complex function of the knee joint: the current understanding of the knee. Knee Surg Sports Traumatol Arthrosc 2015; 23(10):2780-2788.

3. Wilson SM, Mehta N, Do HT, Ghomrawi H, Lyman S, Marx RG. Epidemiology of multiligament knee reconstruction. Clin Orthop Relat Res 2014; 472(9):2603-2608.

4. Schenck RC, Jr., Richter DL, Wascher DC. Knee Dislocations: Lessons Learned From 20-Year Follow-up. Orthop J Sports Med 2014; 2(5):2325967114534387.
These two studies have in common that they found an inferior outcome in older age groups after multi-ligament injury of the knee. However, the message is not unambigously clear as it appears at first glance. Several correlations appear not to be significant and even contradictory.

Clearly, the present study shows no significant correlation between age and several major outcome parameters. One strength of the present study is the rather large number of patients $(n=68)$ treated, despite being such a rare injury. This study reports complete results on the long-term outcomes throughout the long follow-up of $12 \pm 8$ years. Another strength is the high number of evaluated parameters, thus leading to a comprehensive analysis. In addition, this is a consecutive single centre series which keeps the sample rather homogenous and finally makes the results comparable with others.

As all retrospective studies this study might have the inherent problem of selection bias and confounding factors. The selection bias is limited due to the fact that it was a consecutive series. Confounding factors were attributed to by using a comprehensive, rather complete clinical analysis.

The present study showed no correlation between the age of patients at time of injury or last follow-up and clinical outcomes after multi-ligament knee injuries. Hence, treatment algorithms should not be based on age as single differentiating factor.

\section{Acknowledgements}

We would like to acknowledge the professional statistician Felix Amsler, MSc for his statistical analysis.

\section{Conflict of Interest}

There is no conflict of interest with regards to this paper.

5. King AH, Krych AJ, Prince MR, Sousa PL, Stuart MJ, Levy BA. Are meniscal tears and articular cartilage injury predictive of inferior patient outcome after surgical reconstruction for the dislocated knee? Knee Surg Sports Traumatol Arthrosc 2015; 23(10):3008-3011.

6. King AH, Krych AJ, Prince MR, Pareek A, Stuart MJ, Levy BA. Surgical Outcomes of Medial Versus Lateral Multiligament-Injured, Dislocated Knees. Arthroscopy 2016; 32(9):1814-1819.

7. Barrett IJ, Krych AJ, Pareek A, Johnson NR, Dahm DL, Stuart MJ, et al. Short- to mid-term outcomes of anatomic MCL reconstruction with Achilles tendon allograft after multiligament knee injury. Knee Surg Sports Traumatol Arthrosc 2018. doi: 10.1007/s00167-018-4843-4. 
8. Woodmass JM, Johnson NR, Mohan R, Krych AJ, Levy BA, Stuart MJ. Poly-traumatic multi-ligament knee injuries: is the knee the limiting factor? Knee Surg Sports Traumatol Arthrosc 2017. doi: 10.1007/s00167-017-4784-3.

9. Krych AJ, Giuseffi SA, Kuzma SA, Stuart MJ, Levy BA. Is peroneal nerve injury associated with worse function after knee dislocation? Clin Orthop Relat Res 2014; 472(9):2630-2636.

10. Darabos N, Gusic N, Vlahovic T, Darabos A, Popovic I, Vlahovic I. Staged management of knee dislocation in polytrauma injured patients. Injury 2013; 44Suppl3:S40-45.

11. Hirschmann MT, Meier MD, C FA, Friederich NF. Long-term outcome of patients treated surgically for traumatic knee dislocation: does the injury pattern matter? Phys Sportsmed 2010; 38(2):82-89.

12. Hirschmann MT, Iranpour F, Muller W, Friederich NF. Surgical treatment of complex bicruciate knee ligament injuries in elite athletes: what long-term outcome can we expect? Am J Sports Med 2010; 38(6):1103-1109.
13. Hirschmann MT, Zimmermann N, Rychen T, Candrian C, Hudetz D, Lorez LG, et al. Clinical and radiological outcomes after management of traumatic knee dislocation by open single stage complete reconstruction/repair. BMC Musculoskelet Disord 2010; 11:102.

14. Tegner Y, Lysholm J. Rating systems in the evaluation of knee ligament injuries. Clin Orthop Relat Res 1985 (198):43-49.

15. Lysholm J, Gillquist J. Evaluation of knee ligament surgery results with special emphasis on use of a scoring scale. Am J Sports Med 1982; 10(3):150-154.

16. Levy NM, Krych AJ, Hevesi M, Reardon PJ, Pareek A, Stuart $\mathrm{MJ}$, et al. Does age predict outcome after multiligament knee reconstruction for the dislocated knee? 2- to 22-year follow-up. Knee Surg Sports Traumatol Arthrosc 2015; 23(10):3003-3007.

17. Richter M, Bosch U, Wippermann B, Hofmann A, Krettek C. Comparison of surgical repair or reconstruction of the cruciate ligaments versus nonsurgical treatment in patients with traumatic knee dislocations. Am J Sports Med 2002; 30(5):718-727. 